\title{
INFLUENCE OF ROCK PROPERTIES ON WEAR OF M AND SR GRADE RUBBER WITH VARYING NORMAL LOAD AND SLIDING SPEED
}

\begin{abstract}
Rubbers are interesting materials and are extensively used in many mining industries for material transportation. Wear of rubber is a very complex phenomenon to understand. The present study aims to explain the influence of rock properties on wear of $\mathrm{M}$ and SR grade rubber used in top cover of conveyor belts. Extensive laboratory experiments were conducted under four combinations of normal load and sliding speed. The wear of both the rubber types were analyzed based on the rock properties like shear strength, abrasivity index and fractal dimension. A fully instrumented testing set up was used to study the wear of rubber samples under different operating conditions. In general, wear was higher for M grade rubber compared to SR grade rubber. Increase in shear strength of rocks depicts decreasing trend for the wear of M and SR grade rubber at lower load conditions. Moreover, a higher load combination displays no definite trend in both the rubbers. The strong correlation between the wear of rubber and frictional power for all rubber-rock combinations has given rise to the parameter A, which reflects the relative compatibility between the rubber and rock. Increase of Cerchar's Abrasivity Index of rocks shows gradual enhancement in wear for M grade rubber in all the load and speed combinations whereas, it fails in SR grade rubber due to its higher strength. The wear of rubber tends to decrease marginally with the surface roughness of rocks at highest normal load and sliding speed in M grade rubber. However, the wear of $\mathrm{M}$ and SR grade rubber is influenced by the surface roughness of rocks.
\end{abstract}

Keywords: Rock, Rubber, Wear, Shear Strength, Surface Roughness

\section{Introduction}

Rocks are aggregates of various minerals, whereas quartz is a common mineral found in almost all the rock types. It is one of the hardest minerals on the basis of Mohr' hardness scale. Any rock having higher quartz percentage exhibit higher abrasive characteristics. In mining operations, drill bit wear has been successfully related to the quartz percentage of rocks and widely considered as a relative measure of rocks abrasive property [1,2]. In general, abrasive rocks do not create higher frictional force at the interface [2], since shale has a very low abrasivity index and produced highest frictional force during drilling with diamond impregnated grits $[1,2]$. Compared to various types of rock strength properties, shear strength is considered best for a correlation with the wear of rubber and it has more relevance to the nature of mechanical action that exists at the rubber-rock interface.

The wear of rubber is determined by the surface and bulk mechanical, thermal, physical, chemical properties, macro and micro-geometry of the frictionally interacting bodies, the operating parameters and the working environment. A reliable relationship between the wear of rubber and both the operating variables and material properties is desirable in order to predict wear behaviors of rubber used under different working condi- tions. The wear phenomenon in rubber has so far been given importance mostly by the conveyor belts, tyre manufacturing and other rubber manufacturing companies. The nature of the interactions between rubber and rock surfaces occur at a discrete points of contact and therefore it depends on the relative roughness of the contacting surfaces. Surface roughness is perhaps the single most important variable, which affects frictional performance. Surface roughness in turn is dependent on the grain size and their distribution along with the general profile of the fractured surface and the general texture of the rock. Fractal dimension (FD) is a superior parameter to characterize the surface roughness of the naturally broken rocks. The influence of the surface roughness parameters on the wear of rubber has been highlighted by the various researchers [3] and therefore a similar exercise has been undertaken in the present study.

Although, some properties have been principally identified, there is no sufficient data available in a published form relating a single property or a set of properties of the rock directly influencing the wear. The effect of each of the rock parameters varies in different operating conditions, which complicates the problem of increasing the abrasion resistance of mechanical rubber and rubber products. In addition to them, the influence of some of the rock properties on the wear of rubber material cannot be ignored.

\footnotetext{
INDIAN INSTITUTE OF TECHNOLOGY, KHARAGPUR, WEST BENGAL, INDIA

** KONGU ENGINEERING COLLEGE, ERODE, TAMIL NADU, INDIA

\# Corresponding author: pal.samir09@gmail.com
} 
Detailed studies of the available literature indicate that most of the investigations have addressed to specific issues important to the tyre manufacturing industry. Some of the models have considered [4-11] wear of polymer as a function of either the operating variables such as load/pressure, speed, sliding length/ duration and some of them have included the properties such as the surface roughness, hardness of the counter-face, asperity height, rubber-rock interface and shear strength of the rock [3].

The commercially available abraders such as Du Pont abrader, Craydon-Akron abrasion tester, DIN abrader, NBS tester, PICO abrader, Taber abrasion tester, Martindale abrader, etc. for the measurement of wear of rubber provide wear standards of elastomers to suit a particular application and none of these machines is universally applicable. Therefore, in the present study, a specially designed and fabricated apparatus [12] was used to measure the wear of rubber using rocks as the abrading material. On the basis of all the above considerations, this research aims in comparing the wear of rubber with the rock properties such as shear strength, abrasivity index and FD of the fractured surface of a given rock type. Several tests with many rubber-rock combinations have been performed on the complete instrumented apparatus, incorporating facilities to vary operating parameters like the speed and normal load.

\section{Experimental}

\subsection{Materials}

The rocks such as Quartz, Granite, Sandstone, Limestone I, Limestone II and Shale collected from nearby mines were used and have shear strengths stretching from a minimum of around $7.5 \mathrm{MN} / \mathrm{m}^{2}$ to $25 \mathrm{MN} / \mathrm{m}^{2}$. Two types of wear resistant rubbers ( $\mathrm{M}$ and SR grade) were used and their physical properties are presented in Table 1. The rubber wear studies due to its interaction with various rock types under different working conditions is certainly influenced by the surface, physical and mechanical properties of the rocks. Therefore, the following rock properties have been determined following the standards recommended by the International Society of Rock Mechanics (ISRM) and American Society of Testing Materials (ASTM) as tabulated in Table 2.

TABLE 1

Physical Properties of M and SR Grade Rubber

\begin{tabular}{|c|c|c|c|}
\hline \hline Rubber & $\begin{array}{c}\text { Tensile } \\
\text { Strength (MPa) }\end{array}$ & $\begin{array}{c}\text { Elongation at } \\
\text { Break (\%) }\end{array}$ & Hardness \\
\hline M & 24 & 450 & 60 \\
\hline SR & 31 & 455 & 70 \\
\hline
\end{tabular}

\subsection{Preparation of Rubber and Rock Samples}

In the present investigation, the samples of rubber discs were prepared in the laboratory from the rubber sheets obtained from a rubber industry. Rubber strips of $9 \mathrm{~mm}$ thick, $12.5 \mathrm{~mm}$
TABLE 2

Physico-Mechanical Properties of the Rocks

\begin{tabular}{|c|c|c|c|c|c|c|}
\hline Properties & Quartz & $\begin{array}{l}\text { Gra- } \\
\text { nite }\end{array}$ & $\begin{array}{l}\text { Sand- } \\
\text { stone }\end{array}$ & $\begin{array}{l}\text { Lime- } \\
\text { stone } \\
\text { I }\end{array}$ & $\begin{array}{l}\text { Lime- } \\
\text { stone } \\
\text { II }\end{array}$ & Shale \\
\hline \multicolumn{7}{|c|}{ Physical Properties } \\
\hline Specific Gravity & 2.66 & 2.76 & 2.06 & 2.04 & 2.65 & 2.15 \\
\hline $\begin{array}{c}\text { Density } \times 10^{-2} \\
\left(\mathrm{MN} / \mathrm{m}^{3}\right)\end{array}$ & 2.56 & 2.61 & 2.45 & 2.63 & 2.70 & 2.25 \\
\hline Porosity (\%) & 0.20 & 0.77 & 16.87 & 15.52 & 11.23 & 18.50 \\
\hline \multicolumn{7}{|c|}{ Strength Properties } \\
\hline Tensile (MPa) & 8.69 & 9.00 & 4.99 & 5.20 & 6.35 & 4.64 \\
\hline $\begin{array}{l}\text { Compression } \\
(\mathrm{MPa})\end{array}$ & 188.9 & 169.8 & 44.96 & 47.20 & 59.92 & 48.53 \\
\hline Shear $(\mathrm{M}$ & 25.40 & 20.63 & 8.44 & 11.55 & 12.79 & 7.69 \\
\hline Cohesion (MPa) & 34.5 & 32.0 & 18.0 & 6.0 & 14.0 & 4.0 \\
\hline $\begin{array}{l}\text { Angle of Intern } \\
\text { Friction }(\tan \varphi\end{array}$ & $63^{\circ}$ & $56^{\circ}$ & $42^{\circ}$ & $40^{\circ}$ & $46^{\circ}$ & $42^{\circ}$ \\
\hline \multicolumn{7}{|c|}{ Elastic Properties } \\
\hline Modulus (GPa) & 102 & 92 & 41.6 & 35 & 47.5 & 12.5 \\
\hline $\begin{array}{l}\text { Poisson's Ration } \\
(\mu)\end{array}$ & 0.26 & 0.33 & 0.28 & 030 & 0.24 & - \\
\hline \multicolumn{7}{|c|}{ Dynamic Properties } \\
\hline $\begin{array}{c}\text { Longitudinal wave } \\
\text { velocity }(\mathrm{m} / \mathrm{s})\end{array}$ & 5225 & 4350 & 2000 & 3016 & 3200 & 990 \\
\hline $\begin{array}{c}\text { Shear wave } \\
\text { velocity }(\mathrm{m} / \mathrm{s})\end{array}$ & 4059 & 2851 & 850 & 1280 & 1430 & 690 \\
\hline \multicolumn{7}{|c|}{ Index Properties } \\
\hline Shore Hardness & 82.0 & 76.0 & 41.0 & 26.3 & 35.27 & 35.9 \\
\hline Vickers Hardness & 710 & 630 & 285 & 180 & 240 & 230 \\
\hline Cerchar's Index & 6.8 & 6.1 & 5.6 & 3.4 & 4.8 & 2.6 \\
\hline Quartz Percent & 100 & 37.5 & 42.5 & 10 & 17.5 & 22 \\
\hline Strength Index & 20 & 20 & 3.4 & 6.3 & 8.24 & 5.54 \\
\hline
\end{tabular}

wide and $165 \mathrm{~mm}$ long were cut and glued to the outer surface of a circular aluminum disc of $44 \mathrm{~mm}$ diameter and $12.5 \mathrm{~mm}$ thick. The ends of the rubber strip were lap jointed to obtain a strong joint of a smooth outer surface. The hub of the aluminum disc has a collar of $12.5 \mathrm{~mm}$ thickness with a central hole of $12.5 \mathrm{~mm}$ diameter. The disc can be mounted on the step-cone pulley shaft by means of a 3/16 BSW set screw. The outer diameter of the circular rubber disc is $62 \mathrm{~mm}$ and the other dimensional details are already published [12]. Similarly, the cylindrical rock samples of $22 \mathrm{~mm}$ diameter were drilled with the impregnated diamond core drill bit in the laboratory. The core was sheared in a specially-fabricated device to get a natural rough surface oriented approximately normal to their long axis. The length of these rock samples were to be kept between 40 to $80 \mathrm{~mm}$ for a proper grip in the rock holder.

\subsection{Working Conditions}

The experiments were carried out for four different combinations of normal load $(7 \mathrm{~N}$ and $21 \mathrm{~N})$ and sliding speed $(0.8 \mathrm{~m} / \mathrm{s}$ and $3 \mathrm{~m} / \mathrm{s}$ ). Because, a similar trend is observed for the other loads and speeds in between these lower and higher limits. The results 
were obtained and graphs are drawn for the same. In-order to study the wear phenomenon of rubber for various combinations of rubber-rock interfaces when subjected to different levels of operating conditions, two stages of laboratory experiments were performed. First stage: To estimate the roughness of rock contact surfaces using a profilometer to obtain the roughness profiles. Second stage: wear investigations of rubbers were performed for four different combinations of normal load and sliding speed for each rocks and rubber types. These tests were framed to study the wear characteristics of each rubber-rock combinations.

\subsection{Surface Roughness Measurement of Rocks}

Surface roughness of naturally broken rocks has a direct influence on the wear of rubbers. Broken samples (22 mm dia) with natural roughness surface were placed on the rock holder for physical measurement of the surface profiles. A stylus type mechanical profilometer consists of two mutually perpendicular dial gauges and a rugged horizontal sliding bar was fabricated in the laboratory. Vertical dial gauge enter into very minute asperities of the rock surface and horizontally oriented dial gauge measures the horizontal movement of the pin along the rock surface during sliding. In addition, a micrometer was attached to provide minute sliding bar movement. First set of readings on both the dial gauges were taken. A small horizontal movement was given after lifting the pin from the rock surface and then it was placed back gently on the rock. The next sets of readings were recorded. In this way, after every small horizontal increment of the sliding bar, a pair of dial gauge reading was taken till other end of the diametric line was reached. The least count of both the dial gauges were $0.01 \mathrm{~mm}$. Nearly 200 readings were taken along each of the five diametric lines of a single rock except for granite and quartz where only about 110 readings could be taken along a line as these samples were of $12 \mathrm{~mm}$ diameter. Once measurement along one line is completed, the rock sample is rotated through an angle of $36^{\circ}$, in order to set the next diametric line. The next set of profilometer readings on both the dial gauges were taken in the same manner as per the above procedure.

\subsection{Wear Apparatus and Test Parameters}

The existing experimental set up was used to measure wear loss of $\mathrm{M}$ and SR grade rubber by varying the normal load and speed. The aluminum wheel covered by a rubber strip of $M$ and SR grade was rotated by a motor through varying speed step-cone type V-belt drive. The naturally fractured rock specimen holder was connected to a long cantilever arm through an octagonal ring type dynamometer. The balancing mass was used to counter balance the weight of cantilever beam and rock holder with dynamometer. The oil dashpot and damping plates are used for vibration damping. The normal load was applied by different hanging weights. In this setup, instrumentation was provided to control the duration of contact, to measure frictional interface temperature and number of revolutions of the rubber disc. Static calibration of normal load was performed and their deflections were recorded. The steps mentioned above were repeated several times till the rubber wheel makes about a total of 100 revolutions. Both the rock sample and rubber disc were weighed accurately to fourth decimal place of a gram to measure the abrasion loss. With a rotation of $45^{\circ}$ the rock sample was mounted again to repeat the experiment on the same rubber wheel following the procedures described above. Similar experiments were carried out till 1000 revolutions on a single rock-rubber pairs are completed. To minimize the error further, the same rock sample of a particular rock type was used for both the load and speed variations. The experiments with all the combinations of normal load and speed for all the rock types with $\mathrm{M}$ grade as well as SR grade rubber were considered in the present investigation.

\section{Results and Discussion}

\subsection{Rock surface roughness estimation by FDs}

The surface profiles of the rock types were obtained based on the profilometer readings and the same was presented in Fig. 1. Shale and Sandstone have fine asperities compared to other rocks. Quartz and Limestone I have relatively flatter surface with less number of asperities. Out of various methods for computations of FDs, box counting method was used because of its simplicity. FD values of the profilometer data sets of all the rock types were computed and presented in Table 3. As a finding,
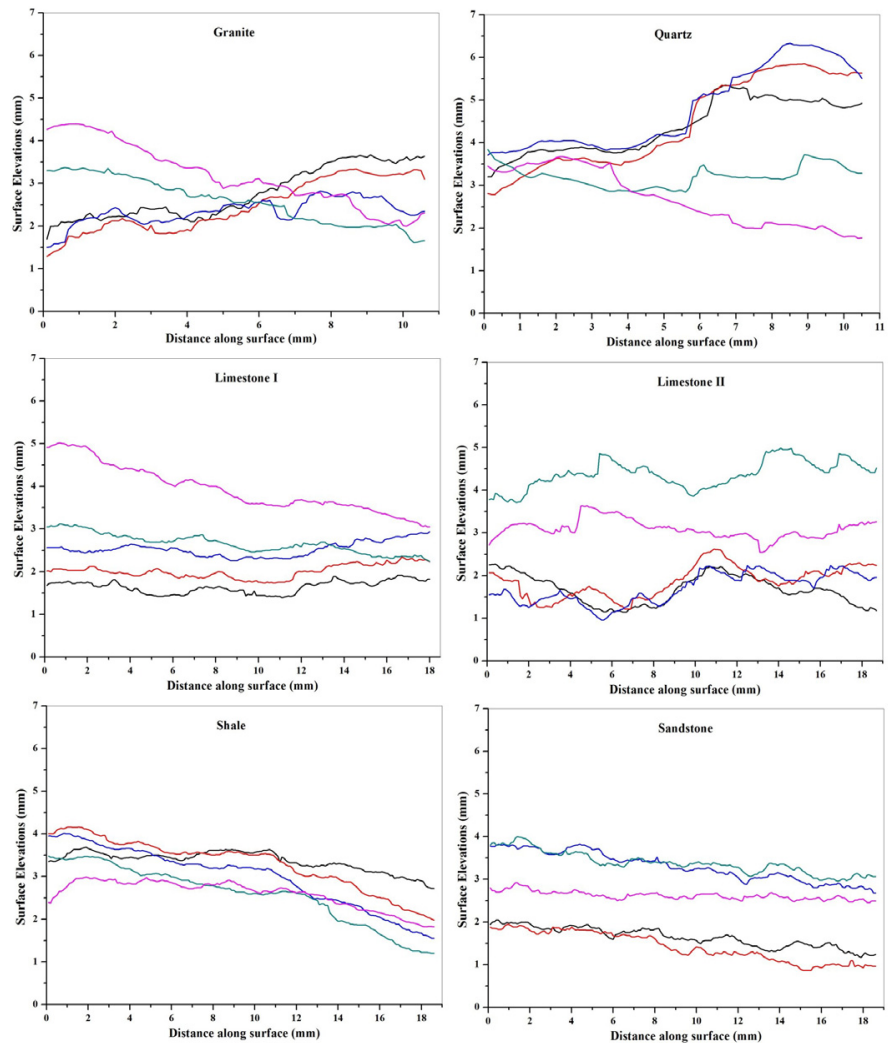

Fig. 1. Five Different Roughness Profiles of Rocks 
it may be noted that Limestone II has the highest roughness and Quartz is lowest compared to all the rock types.

TABLE 3

Fractal Dimension of Rock Surface Profiles

\begin{tabular}{|c|c|c|c|c|c|c|}
\hline \hline Rock & Quartz & Granite & $\begin{array}{c}\text { Sand- } \\
\text { stone }\end{array}$ & $\begin{array}{c}\text { Lime- } \\
\text { stone I }\end{array}$ & $\begin{array}{c}\text { Lime- } \\
\text { stone II }\end{array}$ & Shale \\
\hline Line 1 & 1.0434 & 1.1491 & 1.1797 & 1.1639 & 1.1981 & 1.1104 \\
\hline Line 2 & 1.0492 & 1.1516 & 1.1767 & 1.1610 & 1.1898 & 1.1088 \\
\hline Line 3 & 1.0421 & 1.1546 & 1.1754 & 1.1621 & 1.1871 & 1.1075 \\
\hline Line 4 & 1.0503 & 1.1554 & 1.1810 & 1.1645 & 1.1929 & 1.1052 \\
\hline Line 5 & 1.0455 & 1.1488 & 1.1795 & 1.1615 & 1.1958 & 1.1101 \\
\hline Mean & 1.0461 & 1.1519 & 1.1785 & 1.1626 & 1.1927 & 1.1084 \\
\hline
\end{tabular}

\subsection{Influence of Roughness of Rock Surface on the Wear of Rubbers}

Fig. 2 \& Fig. 3 explains that both $\mathrm{M}$ and SR grade rubber projected almost similar characteristics of wear with the surface

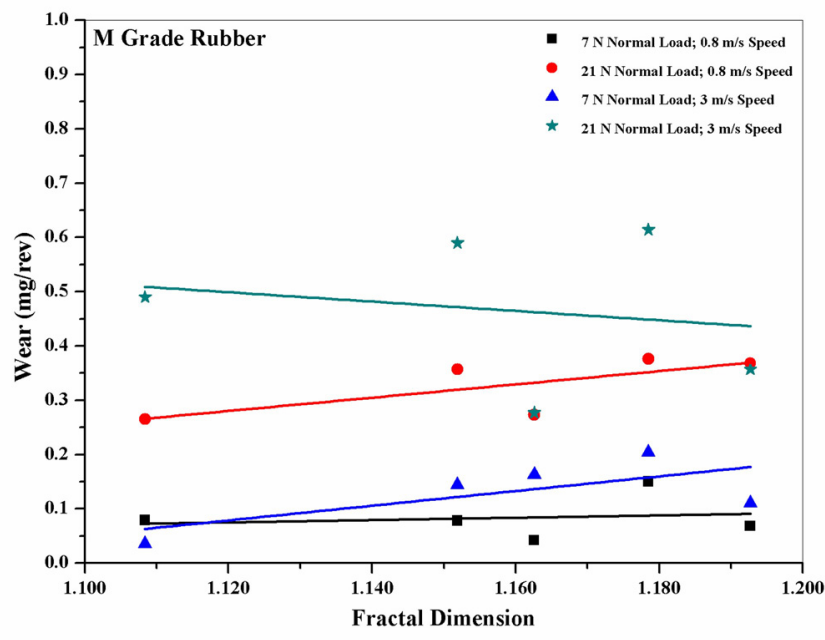

Fig. 2. Variation of Wear with Fractal Dimension of Rock Surface for M Grade Rubber

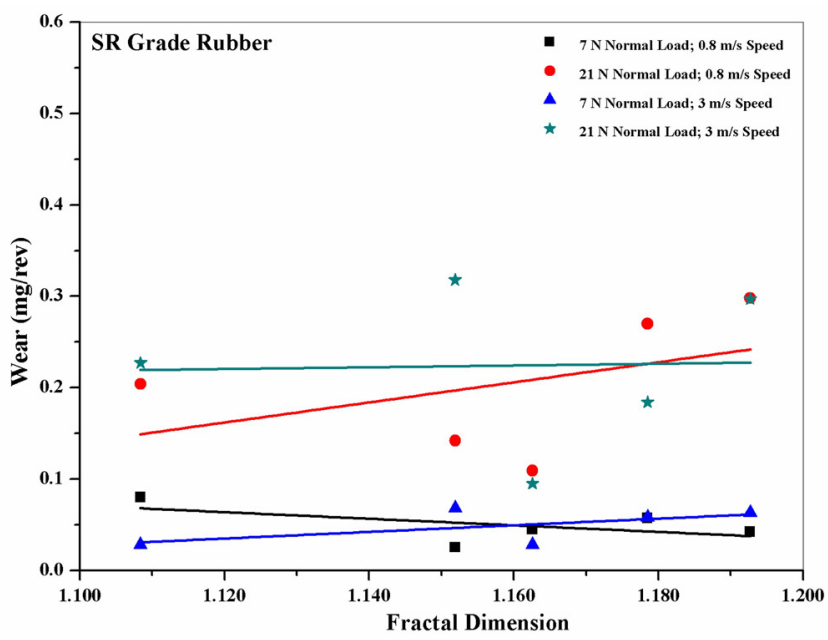

Fig. 3. Variation of Wear with Fractal Dimension of Rock Surface for SR Grade Rubber roughness of rocks at lower load operating conditions. It may be due to the fact that the rock grains are not able to indent into the rubber surface at a minimum load of $7 \mathrm{~N}$. At higher load operating conditions, the increase in wear of both the rubbers with increase in roughness was observed, which is as expected at higher loads. But in the case of higher load and higher speed combination, grains of rough surfaces of rocks gets dislodged even at the very early contact periods, thus it leaves behind a blunt and smoother surfaces which shows marginal decrease in wear of soft $\mathrm{M}$ grade rubber.

\subsection{Variation in Wear of Rubbers with respect to Shear Strength of Rocks}

Fig. 4 \& Fig. 5 demonstrate a relationship between the shear strength of rocks and wear of M and SR grade rubber. The results render linear decrease in wear of both $\mathrm{M}$ and SR grade rubber with increase in shear strength of rocks for lower normal load and lower sliding speed. However, lower normal load and

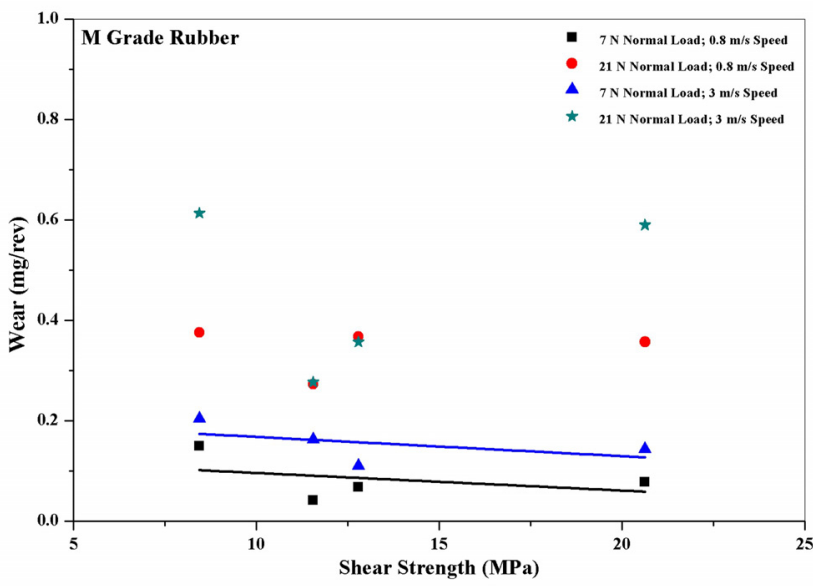

Fig. 4. Variation of Wear of M Grade Rubber with Shear Strength of Rocks

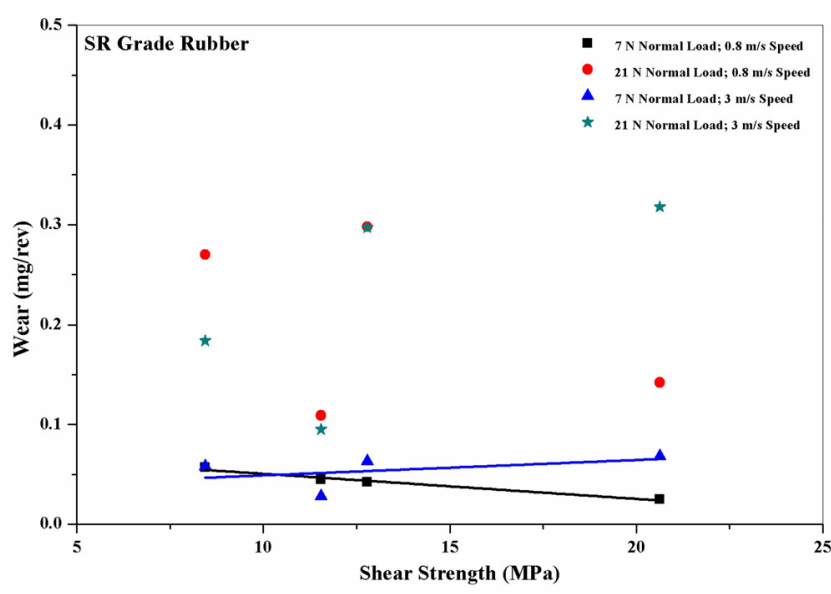

Fig. 5. Variation of Wear of SR Grade Rubber with Shear Strength of Rocks 
higher speed depicts decreasing trend in soft $\mathrm{M}$ grade rubber and increasing trend in hard SR grade rubber. In addition, a higher load combination displays no definite trend in both the rubbers. As an observation, compared to shear strength of rocks, the roughness of fractured rock surface plays a more predominant role in wear of both the rubbers.

\subsection{Effect of Cerchar's Abrasivity Index of rocks on the Wear of Rubbers}

Cerchar's Abrasivity Index, which is a standard method of assessing the abrasivity of rocks [1,2] has been compared with wear of both the rubbers as shown in Fig. $6 \& 7$. The graph explains that $\mathrm{M}$ grade rubber displays prominent increasing trend in wear for all the combinations of load and sliding speed. But, SR grade rubber exhibit decreasing trend at lower load and lower speed, whereas it depicts increasing trend with lower load and higher speed. Although there is a general increase in wear values observed in SR grade rubber at higher load operating range, it fails to show any uniform trend with respect to Cerchar's Abrasivity Index of rocks.

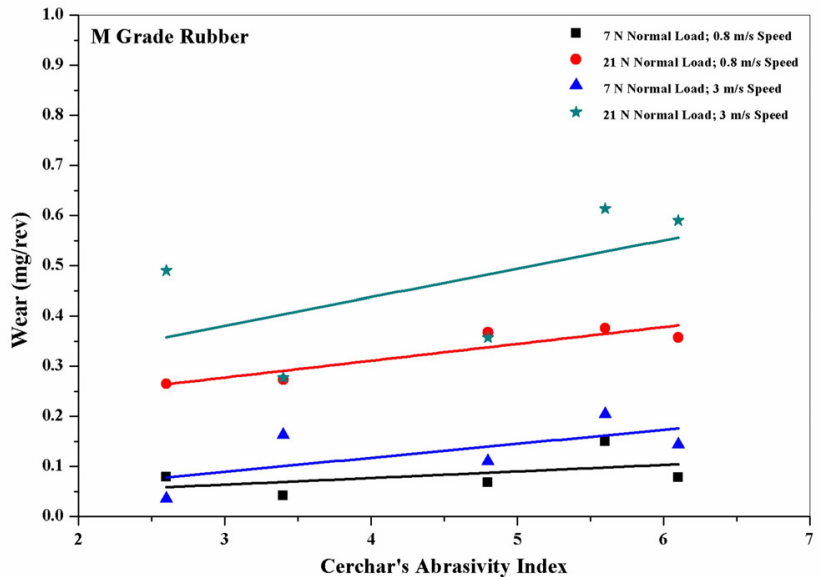

Fig. 6. Variation of Wear of M Grade Rubber with Cerchar's Abrasivity Index of Rocks

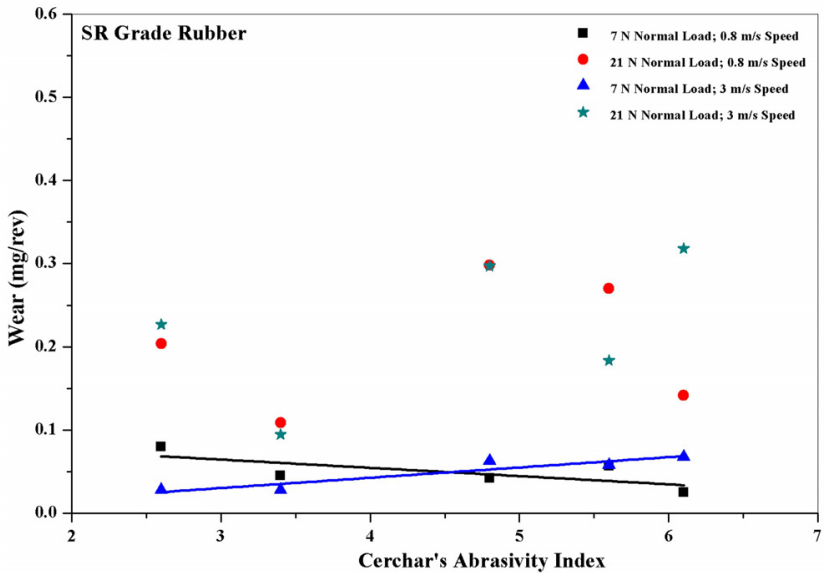

Fig. 7. Variation of Wear of SR Grade Rubber with Cerchar's Abrasivity Index of Rocks

\subsection{Relationship between Wear of Rubbers and Frictional Power (Fp)}

The product of measured frictional force with sliding speed yields the $F p$ generated during the experiments. In addition, the obtained $F p$ correlates with wear of both the rubber and is in line with the general equation (Eq. 1) as follows:

$$
\text { Wear }=(A * F p)+B
$$

Two different sets of graphs (Fig. 8-11) have been generated during the study of wear against $F p$ - (i) for low speed wear tests, where $F p \leq 40$ and (ii) for high speed wear tests, where $F p>40$. The value of $A$ (slope) obtained from the above correlations, which have influence on the wear of both M and SR grade rubber in lower and higher sliding speeds were tabulated in Table 4

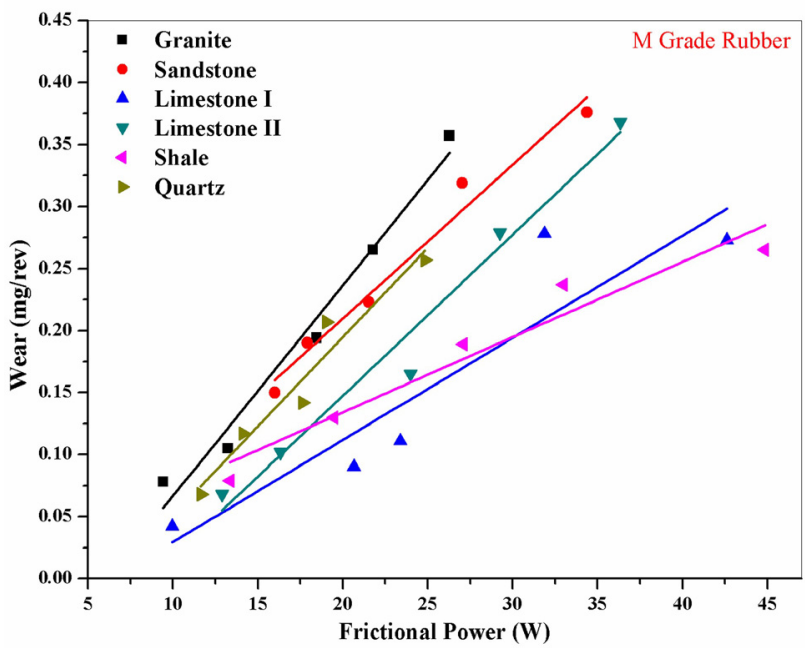

Fig. 8. Effect of Frictional Power on the Wear of M Grade Rubber in Lower Sliding Speed

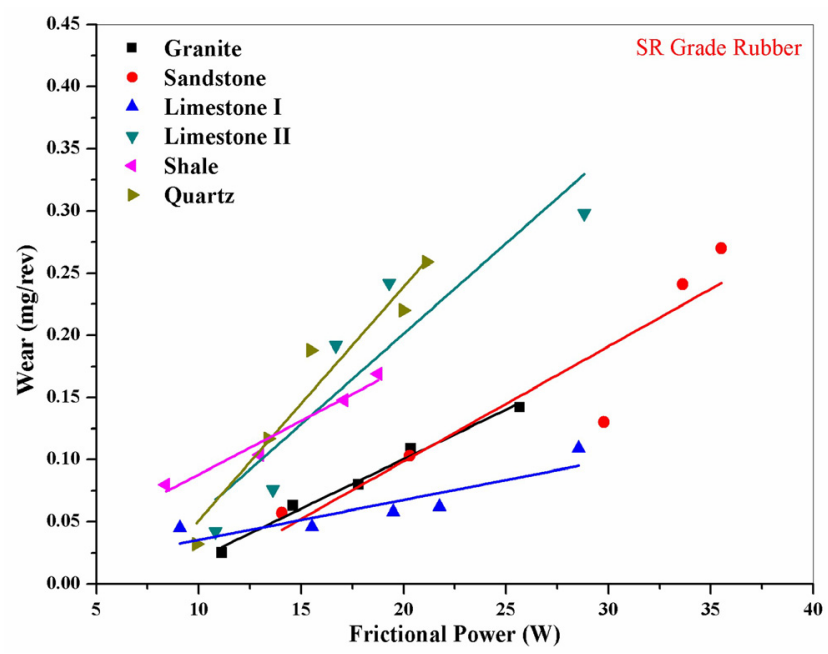

Fig. 9. Effect of Frictional Power on the Wear of SR Grade Rubber in Lower Sliding Speed 


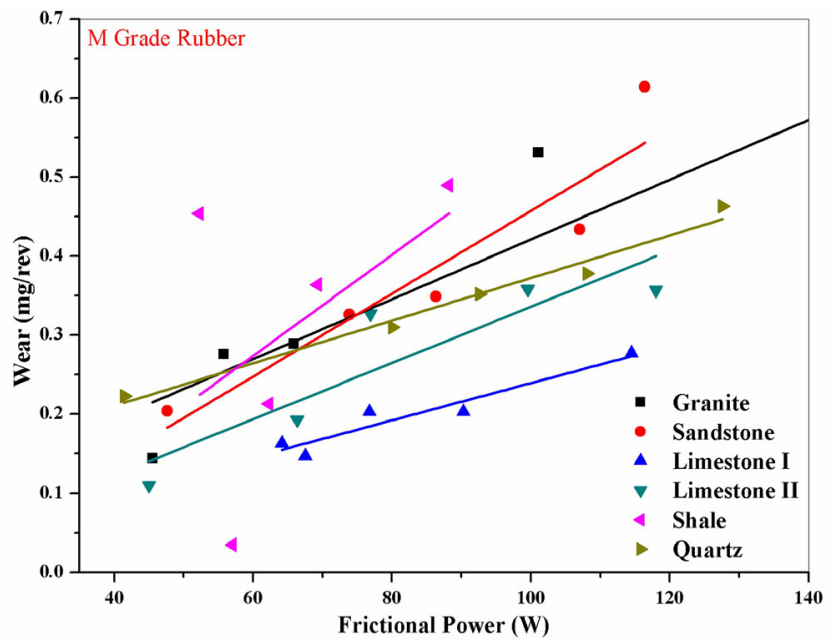

Fig. 10. Effect of Frictional Power on the Wear of M Grade Rubber in Higher Sliding Speed

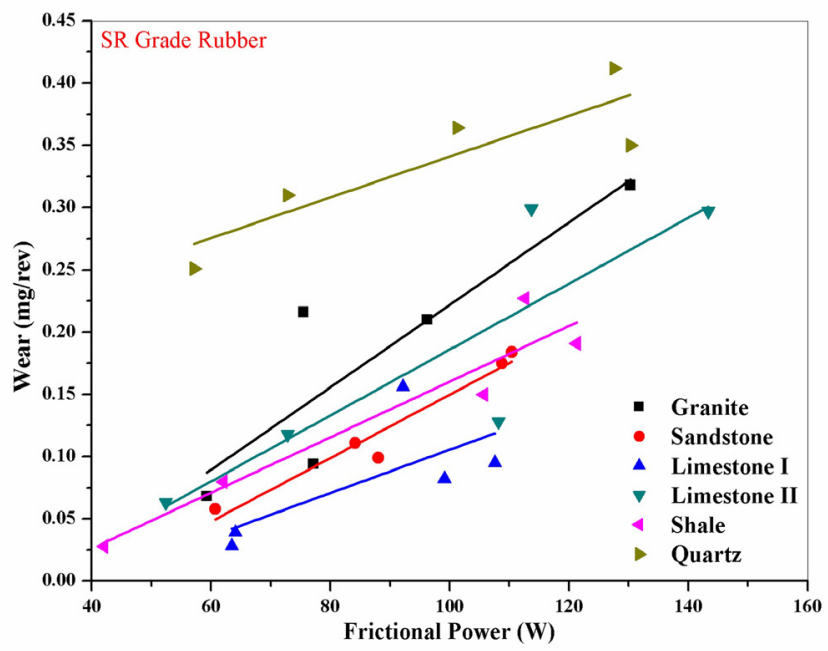

Fig. 11. Effect of Frictional Power on the Wear of SR Grade Rubber in Higher Sliding Speed

TABLE 4

Value of Parameter " $A$ " in Lower and Higher Sliding Speeds

\begin{tabular}{|c|c|c|c|c|}
\hline \multirow{2}{*}{ Rock } & \multicolumn{2}{|c|}{$\begin{array}{c}\text { Low Speed } \\
(0.8 \mathrm{~m} / \mathrm{s})\end{array}$} & \multicolumn{2}{|c|}{$\begin{array}{c}\text { High Speed } \\
(3.0 \mathrm{~m} / \mathrm{s})\end{array}$} \\
\hline & M Grade & SR Grade & M Grade & SR Grade \\
\hline Granite & 0.017 & 0.008 & 0.004 & 0.003 \\
\hline Sandstone & 0.012 & 0.009 & 0.005 & 0.003 \\
\hline Limestone I & 0.008 & 0.003 & 0.002 & 0.002 \\
\hline Limestone II & 0.013 & 0.015 & 0.004 & 0.003 \\
\hline Shale & 0.006 & 0.009 & 0.006 & 0.002 \\
\hline Quartz & 0.014 & 0.019 & 0.003 & 0.002 \\
\hline
\end{tabular}

\subsection{Influence of Shear Strength of Rocks on the Parameter $A$}

The influence of shear strength on parameter $A$ with varying sliding speeds for both M and SR grade rubber is shown in
Fig. $12 \&$ Fig. 13. The general finding is that, with increase in shear strength of rocks, soft $\mathrm{M}$ grade rubber has higher wear with respect to Fp when compared to hard SR grade rubber except in some cases. This may be mainly due to effect of asperities of naturally broken rock surfaces with both the rubbers and rubberrock interfaces in different sliding speeds.

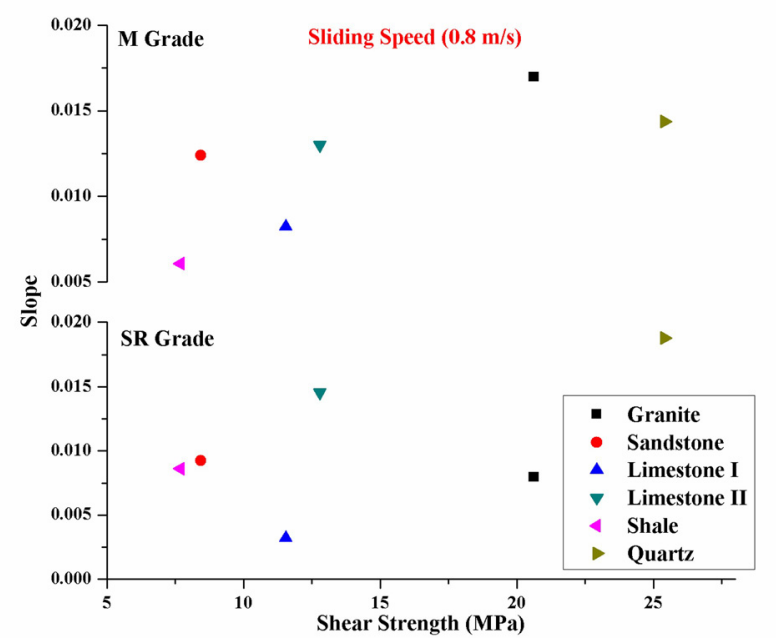

Fig. 12. Influence of Shear Strength on the Parameter $A$ of M and SR Grade Rubber in Lower Speed

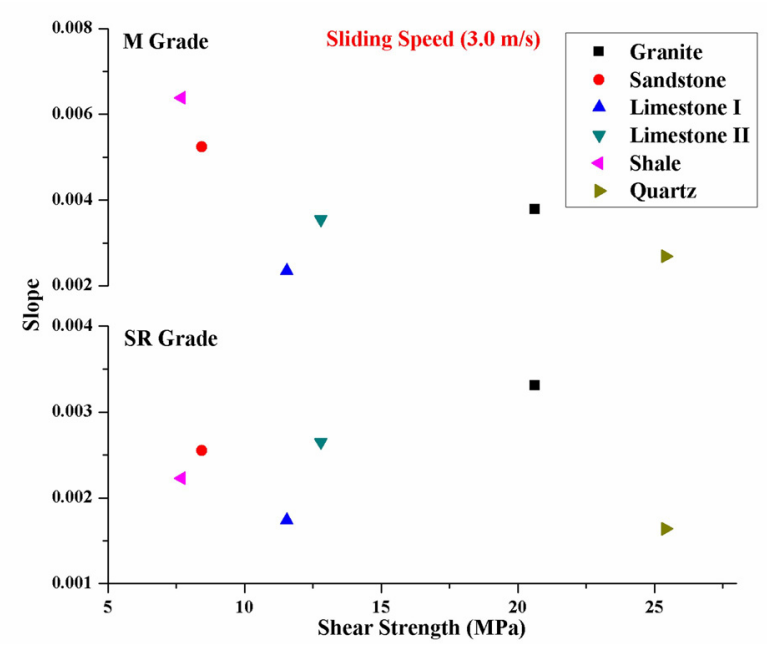

Fig. 13. Influence of Shear Strength on the Parameter $A$ of M and SR Grade Rubber in Higher Speed

\section{Conclusion}

The wear of both M and SR grade rubber showed inconsistent relationship with rock properties like shear strength and Cerchar's Abrasivity Index. The roughness profiles of rocks have good influence on the wear of both the rubber types with varying normal load and speed. A strong linear correlation between the wear of rubber and Fp were obtained and its general form is Wear $=(A * F p)+B$, the slope ' $\mathrm{A}$ ' is lower in SR grade rubber compared to $\mathrm{M}$ grade rubber, indicating a better compatibility of SR grade rubber. However, the slope doesn't have good correlation with shear strength and fractal dimension of rocks. 


\section{REFERENCES}

[1] K.U.M. Rao, Experimental and theoretical investigations of diamond impregnated drilling, Ph.D. thesis, Indian Institute of Technology Kharagpur, India, 1994.

[2] K.U.M. Rao, B. Misra, Principles of rock drilling, A.A. Balkema, 1999.

[3] N. Viswanath, D.G. Bellow, WEAR 181, 42 (1995).

[4] Z. Rymuza, Wear in polymer micro-pairs, Proceedings of $3^{\text {rd }}$ International Conference on Wear of Materials, 125-132 (1981).

[5] S.B. Ratnar, Connection between the wear resistance of plastics and other mechanical properties, Sov. J. Plast. 7, 37 (1964).
[6] R.B. Lewis, Mech. Eng. 86, 32 (1964).

[7] S.K. Rhee, WEAR 16, 431 (1970).

[8] J.K. Lancaster, Friction and wear, in A.D. Jenkin (Ed.), Polymer Science 1972.

[9] J.R. Atkinson, K.J. Brown, D. Dawson, J. Lubr.Technol. 100, 208 (1978).

[10] M.K. Kar, S. Bahadur, WEAR 30, 337 (1974).

[11] E.M. Shvetsova, I.V. Kragelskii, Friction and wear in machines, Collection VIII, Published by USSR, Academy of Sciences 1953.

[12] S.K. Pal, B. Misra, A.K. Bhowmick, Plast. Rub. Compos. Pro. 25, 332 (1996). 